\title{
Investigation of shale gas microflow with the Lattice Boltzmann method
}

\author{
Xiao-Ling Zhang $\cdot$ Li-Zhi Xiao $\cdot$ Long Guo $\cdot$ \\ Qing-Ming Xie
}

Received: 22 January 2014 / Published online: 13 January 2015

(c) The Author(s) 2015. This article is published with open access at Springerlink.com

\begin{abstract}
In contrast to conventional gas-bearing rocks, gas shale has extremely low permeability due to its nanoscale pore networks. Organic matter which is dispersed in the shale matrix makes gas flow characteristics more complex. The traditional Darcy's law is unable to estimate matrix permeability due to the particular flow mechanisms of shale gas. Transport mechanisms and influence factors are studied to describe gas transport in extremely tight shale. Then Lattice Boltzmann simulation is used to establish a way to estimate the matrix permeability numerically. The results show that net desorption, diffusion, and slip flow are very sensitive to the pore scale. Pore pressure also plays an important role in mass fluxes of gas. Temperature variations only cause small changes in mass fluxes. The Lattice Boltzmann method can be used to study the flow field in the micropore spaces and then provides numerical solutions even in complex pore structure models. Understanding the transport characteristics and establishing a way to estimate potential gas flow is very important to guide shale gas reserve estimation and recovery schemes.
\end{abstract}

Keywords Shale gas - Permeability - Adsorption · Desorption · Diffusion · Slip effect

X.-L. Zhang · L.-Z. Xiao $(\bowtie) \cdot$ L. Guo

State Key Laboratory of Petroleum Resources and Prospecting, China University of Petroleum, Beijing 102249, China

e-mail: xiaolizhi@cup.edu.cn

Q.-M. Xie

Key Laboratory of Shale Gas Exploration, Ministry of Land and Resources, Chongqing Institute of Geology and Mineral Resources, Chongqing 400042, China

Edited by Jie Hao

\section{Introduction}

Shale gas, which is hard to exploit, will play an increasingly critical role in China's natural gas production in the future (Jia et al. 2012; Zou et al. 2010; Chen et al. 2012; Sun et al. 2013). The matrix of gas shale consists of fine clay minerals and organic matter, and pore space reduces largely due to the compaction and cementation of these very fine grains (Wang et al. 2013; Li et al. 2007). Organic-rich shale is treated as source rock which has potential to produce natural gas. The pore scale of gas shale is some two orders of magnitude smaller than that of conventional sandstone (Bustin et al. 2008; Loucks et al. 2009). The pore throat diameter of shale is also very small, only dozens of times the size of methane molecules (Curtis et al. 2010). Therefore, permeability of gas shale is extremely low, normally only about tens to hundreds of nanodarcy. The micropore structure and flow characteristics are very complex and not well understood (Huang et al. 2012; Li et al. 2013).

The shale gas production mechanism after fracturing is as follows. First, free gas in the formation fracture networks is transported to the wellbore driven by the pressure difference between the borehole and formation pressures. Then free gas in the pore network flows to the fracture network due to the gas concentration difference between the pore network and fracture network, resulting in reduction of pore pressure. Finally, gas adsorbed on the surface of organic matter will desorb to pore spaces to increase the pore pressure. Overall, natural gas moves from the pore network to the fracture network and finally flows to the wellbore to be collected (Zou et al. 2014).

To estimate how much gas can be produced, it is necessary to evaluate the gas transport ability of the formation rock. It is very difficult to estimate matrix permeability with traditional experimental methods and to predict flow 
ability after fracturing due to the complex flow mechanisms of shale gas. In recent years, a lot of studies have been carried out to study the micro-scale flow characteristics of shale gas, which focus on two aspects as, (1) Laboratory measuring methods consist of the pulse pressure decay method for cores and the gas expansion method for crushed samples. They were developed to overcome long measuring times through applying pulse pressure and reducing the volume of the samples. (2) Numerical simulation methods consist of the molecular dynamics method, finite difference method (Shabro et al. 2009, 2011), finite element method (Roy et al. 2003; Yao et al. 2013), level set method (Prodanovic and Bryant 2007; Prodanovic et al. 2008), and the Lattice Boltzmann method (Tolke et al. 2010; Fathi and Akkutlu 2011; Maier and Bernard 2010).

These methodologies resulted in some research progress which established the theoretical foundation of shale gas flow mechanisms, but quantitative research into adsorption mechanisms and influencing factors for micro-scale gas transport characteristics is still needed. Based on microscale gas flow mechanisms, this paper focuses on various possible factors that affect shale gas flow characteristics, and quantitatively analyzes the influence of each factor. Finally, Lattice Boltzmann simulation is used with complex models to estimate the matrix permeability.

\section{Micro flow mechanisms}

Darcy's law assumes that fluid properties are stable without any physical or chemical reaction with the rock. Only the viscous interaction forces between molecules control the flow without change in the fluid properties (viscosity) and pore geometry (cross-sectional area, length) in the regime of laminar flow. But physical adsorption of methane occurs and gas changes states on the surface of kerogen in organic-rich shale. Shale gas flow is also controlled by molecular diffusion. Due to these inherent characteristics of gas shale such as, (1) widely dispersed organic matter and (2) nano-scale pore system (Zou et al. 2013), shale gas transport mechanisms do not fully follow Darcy's law. We cannot simply use Darcy's law to calculate matrix permeability of gas shale because of these special phenomena and problems (Civan 2010; Civan et al. 2011).

Shale gas flow is controlled by flow mechanisms at different scales such as, (1) adsorption and desorption, (2) diffusion, (3) slip flow, and (4) nonlinear Darcy flow. All these flow mechanisms make the prediction of shale gas transport more and more complicated. Three flow mechanisms in nano-scale pores will be discussed in the following sections. First a parameter which distinguishes different flow regimes will be introduced.

\subsection{Knudsen number}

In 1934, Knudsen defined a dimensionless parameter (Knudsen parameter, $K_{\mathrm{n}}$ ) which reflects the degree of collision between gas molecules when rarefied gas flows in narrow channels. Therefore, gas flow regimes at different scales can be determined by the value of $K_{\mathrm{n}}$ expressed as (Ziarani and Aguilera 2012)

$K_{\mathrm{n}}=\frac{\lambda}{l_{\text {char }}}$,

where $l_{\text {char }}$ is the characteristic value of the geometry through which fluids flow (such as channel height, tube radius, etc.), $\mathrm{m} ; \lambda$ is the mean free path of gas molecules [namely, the average distance traveled by a moving particle (such as an atom or a molecule) between successive impacts (collisions)], $\mathrm{m}$.

Different flow regimes classified by the value of $K_{\mathrm{n}}$ are shown in Table 1. The rarefied effect of gas molecules becomes more and more significant with an increase of $K_{\mathrm{n}}$. For normal shale gas reservoir temperatures (350-450 K) and pressures (25-28 MPa), the mean free path of methane molecules would be between 0.9 and $4.4 \mathrm{~nm}$. If the pore size is $50 \mathrm{~nm}$ diameter, $K_{\mathrm{n}}$ will be $10^{-3}-10^{-2}$ then the flow regime is slip flow. So in nano-scale pore spaces the continuum assumption of fluid flow breaks down and the Navier-Stokes (for short, N-S) equation with no-slip boundaries is no longer valid.

\subsection{Adsorption and desorption}

As shown in Fig. 1a, before well drilling there is dynamic equilibrium in pores of organic matter which means the adsorption and desorption rates are equal. But when the pore pressure reduces, this equilibrium breaks down and net desorption item occurs which will play a complementary role in the mass flux of the pores as shown in Fig. 1b (Parker et al. 2009).

Adsorption mechanisms are very important for shale gas flow. Physical adsorption of supercritical gases at high

Table 1 Flow regimes of Knudsen number

\begin{tabular}{clccl}
\hline $\begin{array}{l}\text { Flow } \\
\text { regimes }\end{array}$ & $\begin{array}{l}\text { Continuum } \\
\text { flow }\end{array}$ & Slip flow & Transition & $\begin{array}{l}\text { Free } \\
\text { molecule } \\
\text { flow }\end{array}$ \\
\hline $\begin{array}{c}\text { Knudsen } \\
\text { number }\end{array}$ & $0-10^{-3}$ & $10^{-3}-10^{-1}$ & $10^{-1}-10^{1}$ & $10^{1}-\infty$ \\
$\begin{array}{c}\text { Equations } \\
\text { Navier- } \\
\text { Stokes }\end{array}$ & $\begin{array}{c}\text { Correctional } \\
\text { Navier- } \\
\text { Stokes } \\
\text { Boltzmann equation }\end{array}$ & $\begin{array}{c}\text { Burnett } \\
\text { equation }\end{array}$ & $\begin{array}{c}\text { Molecular } \\
\text { dynamic }\end{array}$ \\
& & & \\
\hline
\end{tabular}


Fig. 1 a Dynamic equilibrium, b Net desorption
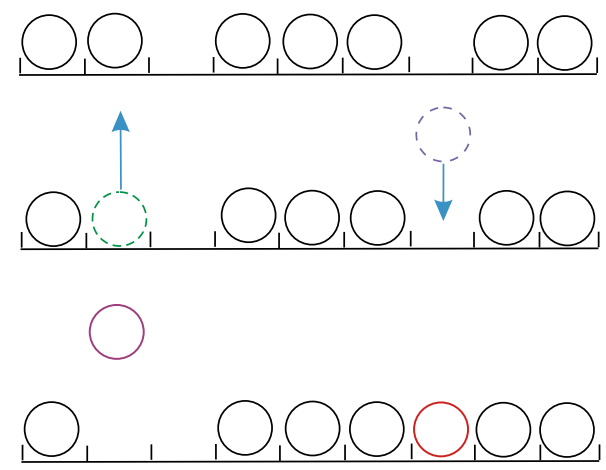

(a)
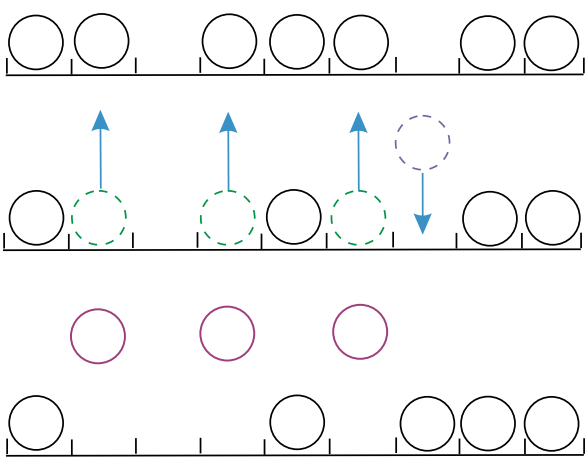

(b) pressures is known to have some unusual features compared to subcritical fluid adsorption. This is important in the understanding of many adsorption processes and presents a challenge for fundamental theoretical research. All methods used for obtaining isotherms (gravimetric, volumetric, piezometric, and total desorption methods, column breakthrough methods, closed-loop recycle methods, and isotope exchange methods) measure the Gibbsian excess rather than the absolute amount adsorbed. In order to evaluate the amount of adsorbed gas in shale, it is necessary to know the absolute adsorption isotherm. A recovered equation of state (EOS) is needed to translate experimental data on excess adsorbed amounts to absolute adsorption data points. According to the Gibbs definition, the excess adsorption amount is given by

$n_{\mathrm{ex}}=\int\left(\rho(z)-\rho_{g}\right) \mathrm{d} V$

where $n_{\mathrm{ex}}$ is the excess adsorbed amount; $\rho(z)$ is the density at coordinates $z$.

The main idea in this study is the application of the nonideal EOS for the corresponding bulk phase to an adsorbed phase, but the parameters of the EOS are modified using the local density and the mean field approximations. The behavior of the adsorption phase obeys the EOS

$R T \ln f^{(a)}+u=R T \ln f$,

where $f^{(a)}$ and $f$ are the fugacities of gas in a pore and in the bulk phase, respectively; $u$ is the overall potential energy of the gas-solid interaction; $T$ is the temperature, $\mathrm{K} ; R$ is the universal gas constant. This equation is valid for subcritical fluids as well.

The force model consists of surface force and longrange Van der Waals forces, which are simulated by a Shan-Chen model (Shan and Chen 1993). On the basis of this operation, $0.5 \mathrm{~nm}$ (approximately the $\mathrm{CH}_{4}$ molecule diameter) lattice unit length is selected. When more adsorbed molecules remain on the surface, other molecules are less likely to be attracted. Therefore, surface force is proportional to $\theta$ which can be written as
$\theta=\frac{P}{P+P_{\mathrm{L}}}-P \cdot A$,

where $P$ is the pressure of gas, $\mathrm{Pa} ; P_{\mathrm{L}}$ is the Langmuir pressure constant, $\mathrm{Pa}$. By fitting a Langmuir isotherm to experimental data, constants $P_{\mathrm{L}}$ and $A$ can be obtained. The bond force between the molecules and the surface is confined to the first layer, and the long-range Van der Waals forces hold other layers. The interactions between molecules are governed by

$\psi=\exp (-1 / \rho)$

where $\psi$ is a function of apparent density; $\rho$ is the density of each lattice unit. For high Knudsen numbers, a combination of bounce back and specular reflection was used to generate the slip effect at the wall. The temperature of the whole gas flow is assumed to be constant. Thus, the pressure can be expressed as

$P_{\mathrm{ads}}=\frac{\rho_{\mathrm{ads}}}{3}+\frac{G}{6}\left(\Psi\left(\rho_{\mathrm{ads}}\right)\right)^{2}$.

The drop of pore pressure leads to a higher desorption velocity compared to adsorption velocity which causes an added flux in the pores as shown in Fig. 2.

\subsection{Diffusion}

From the perspective of molecular dynamics, gas diffusion is actually the result of irregular thermal motion of gas molecules. According to the value of $K_{\mathrm{n}}$, diffusion can be divided into Fickian diffusion, Knudsen diffusion, and transitional diffusion. In nano-scale pores with high Knudsen number, Knudsen diffusion is the dominant flow mechanism.

Knudsen diffusion in nanometer pores can be written in the form of a pressure gradient (Roy et al. 2003). In nanometer pores ignoring the viscosity effect, mass flux due to diffusion caused by molecular concentration difference (Javadpour et al. 2007) can be expressed as

$J_{\mathrm{d}}=\frac{M D_{\mathrm{k}}}{R T} \frac{\Delta P}{L}$. 


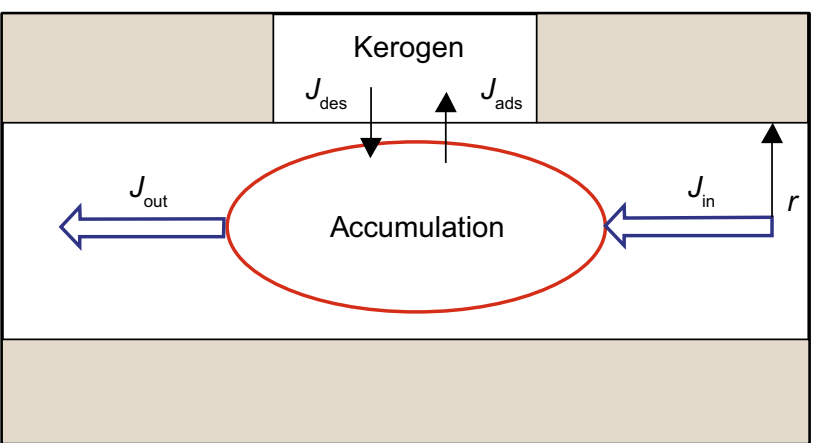

Fig. 2 Net desorption adds gas in the pore

The Knudsen diffusion coefficient $D_{\mathrm{k}}$ can be written as

$D_{\mathrm{k}}=\frac{2 R_{0}}{3} \sqrt{\frac{8 R T}{\pi M}}$,

where $R$ is the universal gas constant, $\mathrm{J} / \mathrm{kmol} \mathrm{K} ; M$ is the molar mass of gas, $\mathrm{kg} / \mathrm{kmol} ; T$ is the temperature, $\mathrm{K} ; \Delta P$ is the pressure difference, $\mathrm{Pa} ; R_{0}$ is the pore radius, $\mathrm{m} ; L$ is the length of the capillary, $\mathrm{m} ; D_{\mathrm{k}}$ is the diffusion coefficient, $\mathrm{m}^{2} / \mathrm{s}$. It indicates that the Knudsen diffusion coefficient $D_{\mathrm{k}}$ is proportional to the pore radius $R_{0}$ and the square root of the temperature $T$.

\subsection{Slip flow}

Free gas in the formation fracture network flows to the borehole due to the difference between the borehole and formation pressures.

The $\mathrm{N}-\mathrm{S}$ equation is the momentum conservation equation which is used to describe the flow of incompressible viscous fluid (continuous flow). For long and straight capillary tubes with a circular cross section, the $\mathrm{N}-$ $\mathrm{S}$ equation can be simplified as

$\frac{\mathrm{d}^{2} v}{\mathrm{~d} r^{2}}+\frac{1 \mathrm{~d} v}{r} \frac{\mathrm{d} r}{\mu L}$,

where $v$ is the flow velocity per unit area, $\mathrm{m} / \mathrm{s} ; \Delta p$ is pressure difference between the ends of the capillary, $\mathrm{Pa} ; \mu$ is the gas viscosity under atmosphere pressure, $\mathrm{Pa} \mathrm{s} ; L$ is the length of the pore. The solution of the above nonlinear difference equations is given by

$v=C_{0}-\frac{\Delta p}{4 \mu L} r^{2}$,

where $C_{0}$ is an unknown constant which can be calculated under different boundary conditions. Velocity equations are solved under two different boundary conditions; continuum flow (Fig. 3a) and slip flow (Fig. 3b) (Zhang et al. 2012; Javadpour 2009).
For continuum flow, fluid can be treated as a unit. The velocities on the pore wall are zero. Mass flux $J_{\text {a_no_slip }}$ caused by pressure difference can be expressed as

$J_{\text {a_no_slip }}=-\frac{\rho_{\text {avg }} R_{0}^{2}}{8 \mu} \times \frac{\Delta p}{L}$

and absolute permeability is given by

$K_{\text {no_slip }}=\frac{R_{0}^{2}}{8}$.

In the case of continuum flow, the mass flux of the fluid depends on the proportional constant $K$, the so-called absolute permeability of the rock, $\mathrm{mD}$. When the parameters such as cross-sectional area, length of the capillary, fluid viscosity, and the pressure difference are fixed, $K$ is an inherent characteristic of the porous medium independent of the fluid used in the measurement.

For slip flow in nano-scale pores, the velocities on the pore wall are no longer zero. So the mass flux $J_{\mathrm{a}_{-} \text {slip }}$ caused by pressure difference can be expressed as

$J_{\mathrm{a} \_ \text {slip }}=-F \times \frac{\rho_{\mathrm{avg}} R_{0}^{2}}{8 \mu} \times \frac{\Delta p}{L}$,

$F=1+\sqrt{\frac{8 \pi R T}{M}} \times \frac{\mu}{R_{0} p_{\text {avg }}} \times\left(\frac{2}{\alpha}-1\right)$.

And absolute permeability is given by

$K_{\text {slip }}=F \times \frac{R_{0}^{2}}{8}$,

where $\rho_{\text {avg }}$ is the average density of the fluid; $R_{0}$ is the radius of the pore; $F$ is the correction factor; $R$ is the universal gas constant (Boltzmann's constant) $=8.314$, $\mathrm{J} / \mathrm{mol} \mathrm{K} ; M$ is the molar mass of the gas, $\mathrm{g} / \mathrm{mol} ; T$ is the temperature, $\mathrm{K} ; p_{\text {avg }}\left[=\left(P_{1}+P_{2}\right) / 2\right]$ is the average pressure in the capillary, $\mathrm{Pa} ; \alpha$ is the dimensionless adjustment coefficient of angular momentum (affected by the surface smoothness of the pore walls, gas type, temperature, and pressure, the range is from 0.65 to 0.85 ).

When the pore scale reduces to nanometers, the slip effect can no longer be ignored and the mass flux due to pressure difference needs to be corrected. The smaller the pore radius is, the larger the value of the correction factor $F$ will be. The flow velocity per unit area considering the slip effect will increase compared to the situation of continuum flow alone.

\section{Lattice Boltzmann method}

The Lattice Boltzmann method is a meso-scale approach to simulating fluid flows. This method intrinsically incorporates micro-scale and meso-scale physical mechanisms. This algorithm is simple, easy to program, highly scalable, 
Fig. 3 Velocity profile. a Continuum flow, b Slip flow

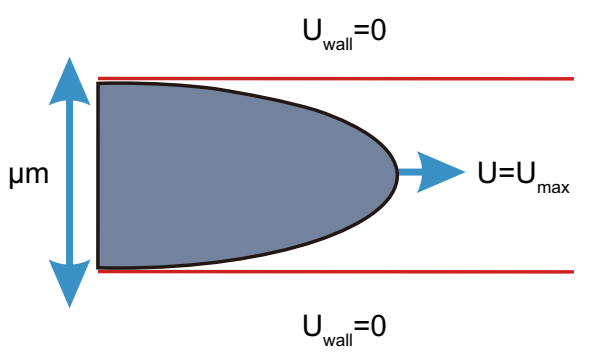

(a)

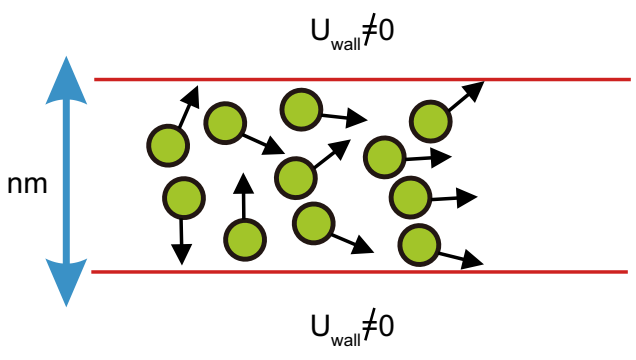

(b) and convenient for dealing with the complex boundaries of porous media, making it very useful for shale gas simulation (Zhang et al. 2014).

The essential ingredients of the LBM are the Lattice Boltzmann equation, the space-filling lattice, and the local equilibrium distribution function. The general form of the Lattice Boltzmann equation is

$f_{a}\left(x_{b}+\Delta t \overrightarrow{e_{a}}, t+\Delta t\right)=f_{a}\left(x_{b}, t\right)+\Omega\left(f_{a}\right) \quad a=0,1, \ldots, N$,

where $f_{a}$ is the distribution function of particles that travel with velocity $\overrightarrow{e_{a}} ; \Omega\left(f_{a}\right)$ is the collision operator which describes changes in particle distribution due to particle collision.

To get correct flow equations it is necessary to use specific lattices that provide sufficient symmetry. The forms of such lattices depend on the dimension of the space. In two dimensions, examples are the square and hexagonal lattices. The nine-speed square lattice known as D2Q9 has been used extensively where each particle moves one lattice unit at its velocity defined by $\overrightarrow{e_{a}}$ [as Eq. (17)] and in one of the eight directions indicated with $1-8$, particle at position 0 is called the rest particle that has a zero velocity.

$e_{a}= \begin{cases}(0,0) & a=9 \\ {\left[\cos \frac{(a-1) \pi}{4}, \sin \frac{(a-1) \pi}{4}\right]} & a=1,3,5,7 \\ \sqrt{2}\left[\cos \frac{(a-1) \pi}{4}, \sin \frac{(a-1) \pi}{4}\right] & a=2,4,6,8\end{cases}$

The Bhatnagar-Gross-Krook (BGK) collision operator with a single relaxation time is often used. The BGK collision operator is derived by linearization of the collision operator around the equilibrium state, neglecting the higherorder terms, and assuming $\Omega_{a}\left(f_{\text {eq }}\right)$ equal to zero. Therefore, the BGK collision operator can be written as Eq. (18)

$\Omega_{a}=\frac{1}{\tau}\left(-f_{a}(x, t)+f_{a}^{\mathrm{eq}}(x, t)\right)$,

where $\tau$ is the relaxation time; $f_{a}^{\text {eq }}$ is the local equilibrium distribution function which defines what type of flow equations are solved using the Lattice Boltzmann equation.

$f_{a}^{\mathrm{eq}}=t_{a} \rho\left(1+\frac{3\left(\overrightarrow{e_{a}} \cdot \vec{u}\right)}{e^{2}}+\frac{9\left(\overrightarrow{e_{a}} \cdot \vec{u}\right)^{2}}{2 e^{4}}-\frac{3(\vec{u} \cdot \vec{u})}{2 e^{2}}\right)$,

where the weights $t_{a}$ are equal to $t_{9}=4 / 9, t_{1}=t_{3}={ }_{5}=t_{7}$ $=1 / 9, t_{2}=t_{4}=t t_{6}=t_{8}=1 / 36$, and $\overrightarrow{e_{a}}$ is the lattice velocity defined as the lattice size $(\Delta x)$ over the lattice time step $(\Delta t)$. Fluid density $(\rho)$ and velocity $(\vec{u})$ are macroscale quantities that can be obtained by Eqs. (20) and (21)

$\rho(x, t)=\sum_{a=1}^{9} f_{a}(x, t)$

$\vec{u}(x, t)=\frac{\sum_{a=1}^{9} f_{a}(x, t) \overrightarrow{e_{a}}}{\rho(x, t)}$

\section{Results and discussion}

In order to study gas flow characteristics in organic-rich shale, both analytical solution and numerical simulation methods are used to represent the transport phenomenon of shale gas. Analytical solutions can reflect the flux variation trend with different parameter values while numerical simulations can show the flow field distribution and estimate the matrix permeability of complicated pore models.

\subsection{Analytical solutions and influencing factors}

Influencing factors of mass flux in nano-scale pores were studied with analytical solutions based on the simplified capillary model.

Based on different pore scales, pressures, and temperatures, etc., mass flux generated by different forces will be analyzed respectively and quantitatively with analytical solutions. Nano-scale pores are very important for shale gas storage and production ability. Pore scale is treated as a sensitive factor to be changed to see how the mass flux changes.

As shown in Fig. 4, when the pore radius reduces to near $10 \mathrm{~nm}$, net desorption and slip flow do not change too 


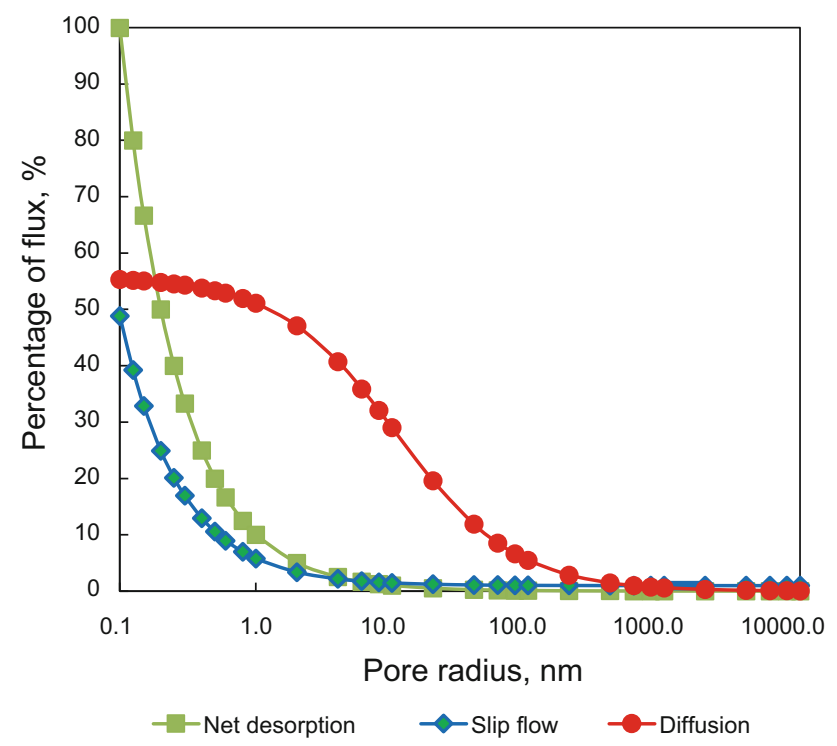

Fig. 4 Mass flux ratio of net desorption, diffusion and slip flow for different pore sizes

much but diffusion increases by $20 \%$. When the pore radius is less than $10 \mathrm{~nm}$, net desorption, diffusion, and slip flow will increase significantly which means the smaller the pores are, the higher the mass fluxes are.

For gas shale under formation conditions, temperature and pressure increase and some shale gas plays are overpressured. Temperatures and pressures are among other factors that need to be discussed. The incremental steps of pressure and temperature are chosen as $0.2 \mathrm{kPa}$ and $50 \mathrm{~K}$.

From Fig. 5 it is easy to find the effect of pressure difference. Mass fluxes change substantially with the variation

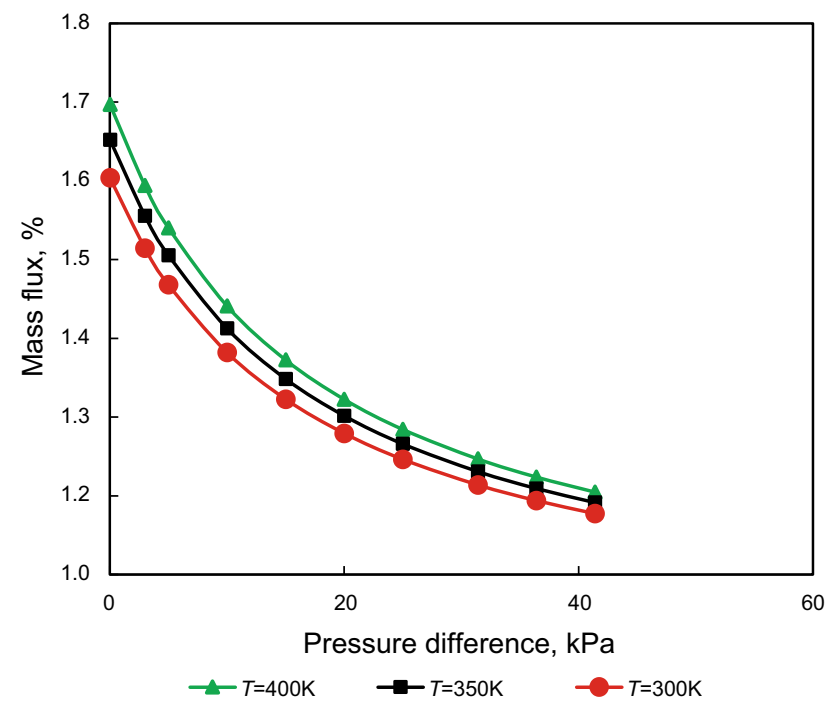

Fig. 5 Mass fluxes under different temperatures and pressures of pressure difference, but change only slightly with temperature. In conclusion, flow flux of gas must be adjusted during the life of the shale gas plays, and permeability measurements in the laboratory must be taken in in situ pressure and temperature conditions, otherwise large errors will be introduced.

\subsection{Numerical simulations}

In the case of complex geometries including holes and cracks, analytical solutions cannot be used, while LBM can be used to simulate the microflow characteristics. The sphere accumulated model is used to simulate the flow in pore spaces. We carried out LBM simulation driven by a constant force on a 3 -D model with $100 \times 100 \times 100$ lattices as shown in Fig. 6a. The radius of the sphere is $40 \mathrm{~nm}$.

Figure $6 \mathrm{a}$ is the accumulation model. Figure $6 \mathrm{~b}$ is the LBM simulation result of the velocity field, the deeper the color, the greater the velocity. Red lines represent the orientation direction of the velocity. For this regular model, porosity is $20 \%$ and permeability calculated with the simulation is $0.003 \mathrm{mD}$.

Another model using spheres of random radius is simulated too as shown in Fig. 7. Pore spaces of the model reduce more than those of the model in Fig. 6 and the porosity is $8 \%$. After simulation the matrix permeability calculated is $23 \mathrm{nD}$ which is much tighter than Fig. 6.

From the simulations above, LBM provides a feasible way to estimate the matrix permeability of gas in tight shale.

\section{Conclusions}

There are significant differences between gas-bearing shale and conventional sandstone. In particular, mobility of shale gas becomes a decisive factor in economic exploitation. In this paper, adsorption/desorption, diffusion, and slip flow mechanisms of shale gas are discussed and some factors like pore scale, pressure, and temperature are studied with analytical solutions. In nano-scale pore spaces of gas shale, gas transport is not only determined by the pore radius, but also significantly influenced by environmental conditions (temperature, pressure). Net desorption, diffusion, and slip play important roles in micro-scale flow which is higher than that calculated by Darcy's law. Lattice Boltzmann simulation on accumulated models is used to establish a technically feasible way to estimate the matrix permeability of complex pore structures. 
Fig. 6 Regular accumulated model and flow field simulation

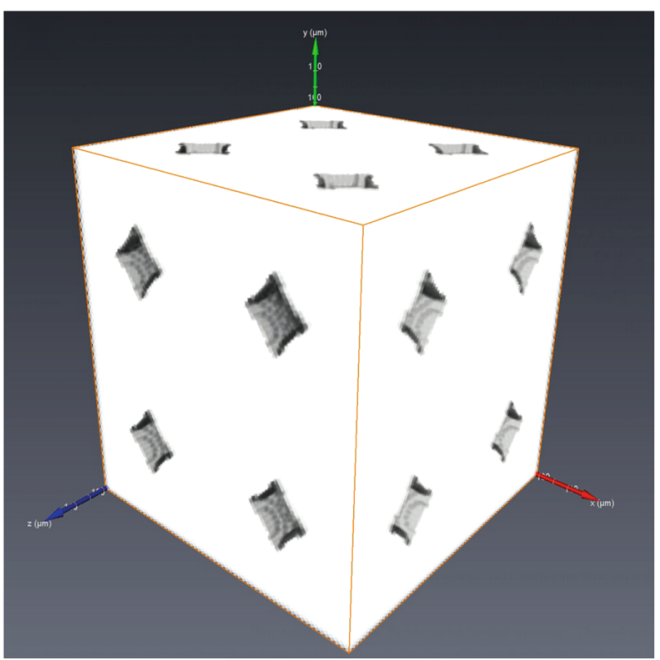

(a)

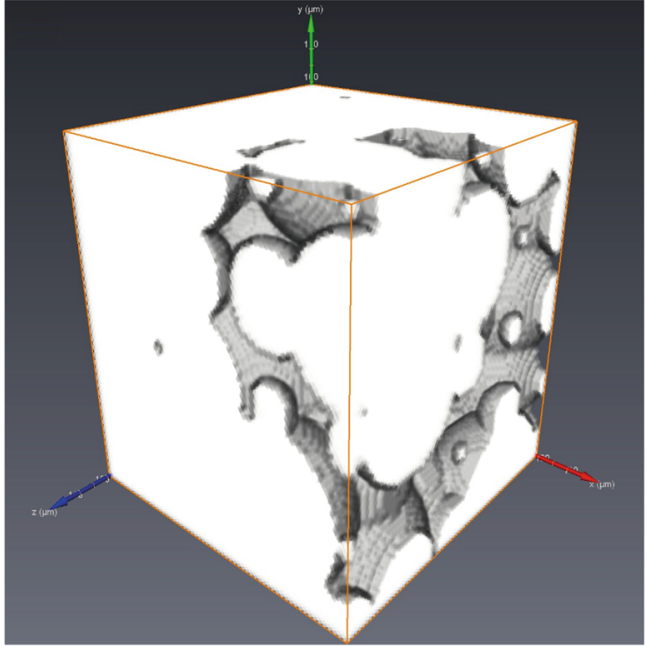

(a)

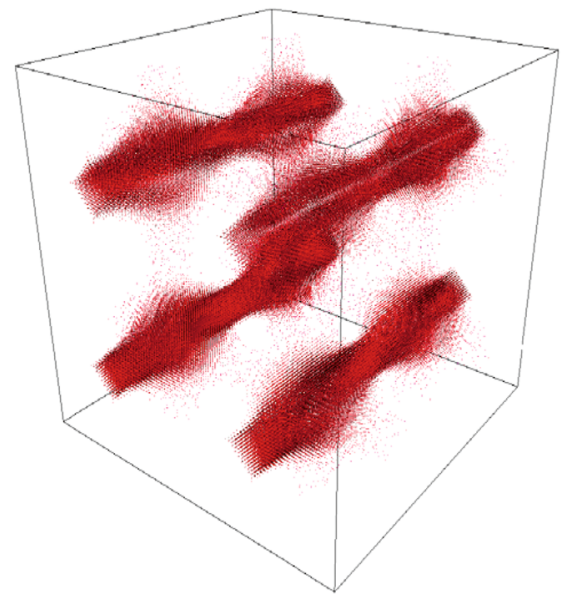

(b)
Fig. 7 Random accumulated model and flow field simulation

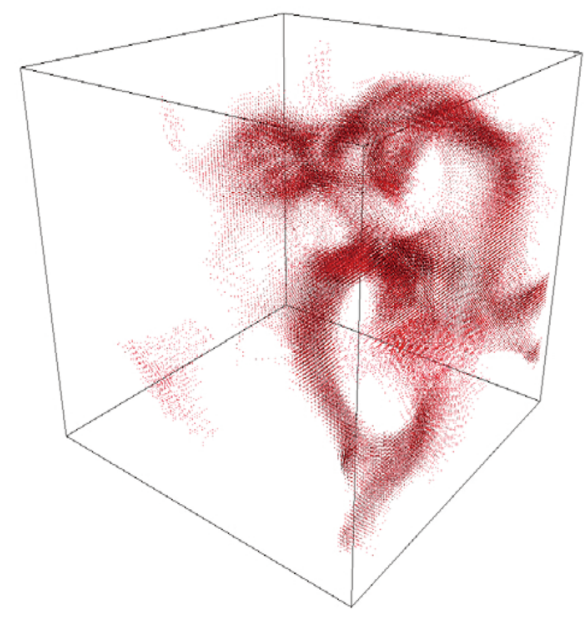

(b)
Acknowledgments This work was supported by the National Natural Science Foundation of China (Grant No. 41130417), "111 Program" (B13010) and Shell Ph.D. Scholarship. The authors thank the valuable comments from Professor Xiaowen Shan.

Open Access This article is distributed under the terms of the Creative Commons Attribution License which permits any use, distribution, and reproduction in any medium, provided the original author(s) and the source are credited.

\section{References}

Bustin RM, Bustin AMM, Cui A, et al. Impact of shale properties on pore structure and storage characteristics. In: SPE Shale gas production conference. Fort Worth, Texas, USA (SPE 119892). 16-18 November 2008.

Chen XJ, Bao SJ, Hou DJ, et al. Methods and key parameters of shale gas resources evaluation. Pet Explor Dev. 2012;39(5):566-71 (in Chinese).
Civan F. Effective correlation of apparent gas permeability in tight porous media. Transp Porous Media. 2010;82(2):375-84.

Civan F, Rai CS, Sondergeld CH. Shale-gas permeability and diffusivity inferred by improved formulation of relevant retention and transport mechanisms. Transp Porous Media. 2011;86(3):925-44.

Curtis ME, Ambrose RJ, Sondergeld CH, et al. Structural characterization of gas shales on the micro- and nano-scales. In: Canadian Unconventional Resources \& International Petroleum Conference. Alberta, Canada (SPE 137693). 19-21 October 2010.

Fathi E, Akkutlu IY. Lattice Boltzmann method for simulation of shale gas transport in kerogen. In: SPE annual technical conference and exhibition. Denver, Colorado, USA (SPE 146821). 30 October-2 November 2011.

Huang JL, Zou CN, Li JZ, et al. Shale gas generation and potential of the lower cambrian Qiongzhusi formation in Southern Sichuan Basin, China. Pet Explor Dev. 2012;39(1):69-75 (in Chinese).

Javadpour F. Nanopores and apparent permeability of gas flow in mudrocks (shales and siltstone). $\mathrm{J}$ Can Pet Technol. 2009;48(8):16-21.

Javadpour F, Fisher D, Unsworth M. Nanoscale gas flow in shale gas sediments. J Can Pet Technol. 2007;46(10):55-61. 
Jia CZ, Zheng M, Zhang YF. Unconventional hydrocarbon resources in China and the prospect of exploration and development. Pet Explor Dev. 2012;39(2):129-36 (in Chinese).

Li XJ, Hu SY, Cheng KM. Suggestions from the development of fractured shale gas in North America. Pet Explor Dev. 2007;34(4): 392-400 (in Chinese).

Li YJ, Feng YY, Liu H, et al. Geological characteristics and resource potential of lacustrine shale gas in the Sichuan Basin, SW China. Pet Explor Dev. 2013;40(4):423-8 (in Chinese).

Loucks RG, Reed RM, Ruppel SC, et al. Morphology, genesis, and distribution of nanometer-scale pores in siliceous mudstones of the Mississippian Barnett Shale. J Sediment Res. 2009;79(12): 848-61.

Maier RS, Bernard RS. Lattice-Boltzmann accuracy in pore-scale flow simulation. J Comput Phys. 2010;229(2):233-55.

Parker MA, Buller D, Petre JE, et al. Haynesville shale-petrophysical evaluation. In: SPE annual technical conference and exhibition. Denver, Colorado (SPE 122937). 14-16 April 2009.

Prodanovic M, Bryant SL. Physics-driven interface modeling for drainage and imbibition in fractures. In: SPE annual technical conference and exhibition. Anaheim, California (SPE 110448). 11-14 November 2007.

Prodanovic M, Bryant SL, Karpyn ZT. Investigating matrix-fracture transfer via a level set method for drainage and imbibition. In: SPE annual technical conference and exhibition. Denver (SPE 116110). 21-24 September 2008.

Roy S, Raju R, Chuang HF, et al. Modeling gas flow through microchannels and nanopores. J Appl Phys. 2003;93(8):4870-9.

Shabro V, Javadpour F, Torres-Verdin C, et al. Diffusive-advective gas flow modeling in random nanoporous systems (RNPS) at different Knudsen regimes. In: Proceedings of the 17th International Conference of Composites or Nano-Engineering. 2009.

Shabro V, Torres-Verdin C, Javadpour F. Numerical simulation of shale-gas production: from pore-scale modeling of slip-flow,
Knudsen diffusion, and Langmuir desorption to reservoir modeling of compressible fluid. In: SPE North American unconventional gas conference and exhibition. The Woodlands, Texas, USA (SPE 144355). 14-16 June 2011.

Shan XW, Chen HD. Lattice Boltzmann model for simulating flows with multiple phases and components. Phys Rev E. 1993;47(3):1815-9.

Sun LD, Zou CN, Zhu RK, et al. Formation, distribution and potential of deep hydrocarbon resources in China. Pet Explor Dev. 2013; 40(6):641-9 (in Chinese).

Tolke J, Baldwin C, Mu YM, et al. Computer simulations of fluid flow in sediment: from images to permeability. Lead Edge. 2010;29(1): $68-74$.

Wang HY, Liu YZ, Dong DZ, et al. Scientific issues on effective development of marine shale gas in Southern China. Pet Explor Dev. 2013;40(5):574-9 (in Chinese).

Yao J, Sun H, Fan DY, et al. Numerical simulation of gas transport mechanisms in tight shale gas plays. Pet Sci. 2013;10(4):528-37.

Zhang WM, Meng G, Wei XY. A review on slip models for gas microflows. Microfluid Nanofluid. 2012;13(6):845-82.

Zhang XL, Xiao LZ, Shan XW, et al. Lattice Boltzmann simulation of shale gas transport in organic nano-pores. Sci Rep. 2014;4:4843.

Ziarani AS, Aguilera R. Knudsen's permeability correction for tight porous media. Transp Porous Media. 2012;91(1):239-60.

Zou CN, Dong DZ, Wang SJ, et al. Geological characteristics, formation mechanism and resource potential of shale gas in China. Pet Explor Dev. 2010;37(6):641-53 (in Chinese).

Zou CN, Yang Z, Zhang GS, et al. Conventional and unconventional petroleum "orderly accumulation": concept and practical significance. Pet Explor Dev. 2014;41(1):14-30 (in Chinese).

Zou CN, Zhang GS, Yang Z, et al. Geological concepts, characteristics, resource potential and key techniques of unconventional hydrocarbon: on unconventional petroleum geology. Pet Explor Dev. 2013;40(4):385-99 (in Chinese). 